\title{
Extensão Popular na formação profissional em saúde para o SUS:
}

refletindo uma experiência*

\author{
Maria Francilene Leite ${ }^{(a)}$ \\ Kátia Suely Queiroz Silva Ribeiro(b) \\ Ulisses Umbelino dos Anjos ${ }^{(c)}$ \\ Patrícia Serpa de Souza Batista(d)
}

\section{Introdução}

A Educação Popular (EP) tem sido concebida de diversas formas, o que dificulta uma conceituação única, universal. Essas diferentes concepções acarretam ações ditas educativas populares com especificidades próprias, distintas e, às vezes, até antagônicas. No entanto, há elementos que obrigatoriamente constituem o arcabouço da Educação Popular sistematizada por Paulo Freire, ou seja, a presença do diálogo, de relações horizontais, da problematização, da aproximação com os espaços populares marginalizados, do compromisso social e da transformação social. Trata-se, portanto, de uma práxis educativa libertadora que apresenta intencionalidade política clara - promover a superação da opressão por meio da conscientização, da análise crítica da realidade, da valorização cultural e do exercício da capacidade de direção política dos oprimidos ${ }^{1}$.

A Educação Popular tem reorientado não só o processo de ensino-aprendizagem ou a relação educador/educando, mas tem contribuído significativamente na maneira como os indivíduos - que a conhecem e a vivenciam - posicionam-se e relacionam-se com o mundo e em sociedade. Dessa maneira, pode-se dizer que a EP tem a possibilidade de se ampliar da área da educação, atingindo outras áreas do conhecimento como a filosofia, ciências da religião e saúde.

A integração da EP com a saúde tem contribuído para a superação do biologicismo e das relações verticais e autoritárias, historicamente presentes entre o profissional de saúde e o sujeito no seu processo de adoecimento ${ }^{2}$. Vasconcelos ${ }^{2}$ considera a EP uma estratégia para aproximação do saber científico, bem como dos serviços de saúde, com a dinâmica de adoecimento e cura do mundo popular, promovendo ações de saúde mais integrais e mais adequadas à vida da população.

Com o processo de estruturação do Sistema Único de Saúde (SUS), a sociedade brasileira passa a ter acesso a uma rede de serviços básicos de saúde que, por meio da Estratégia Saúde da Família (ESF) em expansão, apresenta o principal meio de reorientação da atenção à saúde. Nesse contexto, milhares de profissionais da saúde estão sendo inseridos no cotidiano do mundo popular e, muitos deles, ainda apresentam uma formação universitária centrada em procedimentos técnicos curativos, com exercício de uma prática clínica individualizada, mantendo relações autoritárias com os usuários e, consequentemente, inapropriadas para a efetivação dos princípios do SUS.

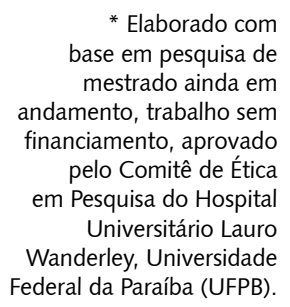

\footnotetext{
(a) Programa de PósGraduação em Modelos de Decisão e Saúde, UFPB. Rua Deputado José Mariz, $\mathrm{n}^{\circ}$ 1040, Tambauzinho. João Pessoa, PB, Brasil. 58042-020.

cilene_|@yahoo.com.br (b) Departamento de Fisioterapia, Centro de Ciências da Saúde, UFPB. João Pessoa, PB, Brasil. katiaqsribeiro@yahoo. com.br (c) Departamento de Estatística, Centro de Ciências Exatas e da Natureza, UFPB. João Pessoa, PB, Brasil. ulissesanjos@gmail.com (d) Departamento de Enfermagem Clínica, Centro de Ciências da Saúde, UFPB. João Pessoa, PB, Brasil. patriciaserpa@oi.com.br.
} 
Embora haja um movimento nacional crescente de incentivo às ações de saúde, orientadas pela Educação Popular, e seja clara a sua importância para a prática educativa, essa perspectiva ainda se encontra distante da matriz curricular das universidades de todo o país. Essa distância dificulta a formação de profissionais, voltada para uma perspectiva inclusiva, ou seja, de superação dos métodos tradicionais e autoritários presentes na educação e na prática em saúde para uma atuação humana, ética e horizontal que, ao aproximar-se do sujeito no seu processo de adoecimento, o trabalhador da saúde possa favorecer a superação da opressão e da exclusão social.

A formação de profissionais de saúde coerente com o SUS passa pela mudança no paradigma biomédico ainda vigente, pela conscientização dos trabalhadores de saúde, pelo maior suporte da administração universitária às atividades no ambiente comunitário e pela superação do preconceito dos estudantes em relação à atuação nos serviços públicos. Nesse sentido, a extensão universitária torna-se uma alternativa adiante da rigorosidade do ensino universitário, sendo um espaço privilegiado para a construção de propostas pedagógicas inovadoras.

No ambiente universitário, existem diversas maneiras de pensar e de fazer extensão, porém há uma prática extensionista, baseada nos preceitos da EP, que apresenta intencionalidade política clara, priorizando o diálogo, o protagonismo estudantil e comunitário, a afetividade, o respeito ao senso comum, à cultura, o compartilhamento das experiências e a indissociabilidade entre universidade e sociedade ${ }^{3,4,5}$. Esse tipo de extensão também tem um caráter transformador, inquietante e libertador e recebe o nome de Extensão Popular.

Na Universidade Federal da Paraíba (UFPB), a Extensão Popular está bastante associada ao Projeto Educação Popular e Atenção à Saúde da Família (Pepasf). Trata-se de uma extensão popular interdisciplinar que atua junto à Comunidade Maria de Nazaré, localizada na periferia de João Pessoa, $\mathrm{PB}$, há 15 anos. Nela, o estudante desenvolve atividades de visitas domiciliares semanais, participa do movimento comunitário já existente, das atividades junto à Unidade Básica de Saúde, participa de lutas sociais e de grupos de cuidado.

O Pepasf é um projeto de ampla atuação e que, juntamente com outros projetos de Extensão Popular, forma o Programa de Educação Popular em Saúde (Progeps). Assim, centenas de estudantes da UFPB e de outras instituições dos mais variados cursos têm a oportunidade de participar desse tipo de extensão, influenciando e sendo influenciado por ela.

Nesse contexto, o objetivo deste estudo é abordar a influência da Extensão Popular na formação universitária em saúde para o SUS, considerando a vivência de uma estudante de enfermagem. Essa experiência está sendo objeto de estudo no curso de mestrado da autora e seus orientadores.

As experiências aqui relatadas são fontes de uma observação participante que permitiu ao pesquisador se inserir no grupo observado, tornando-se parte dele, interagindo e partilhando o seu cotidiano para sentir o que significava estar naquela situação ${ }^{6}$. Os aprendizados adquiridos nas atividades de visitas domiciliares, reuniões semanais e espaços de articulação política comunitária do projeto serão discutidos a seguir, considerando a sua contribuição para formação profissional em saúde e atuação junto ao SUS. É válido ressaltar que os aprendizados aqui relatados são singulares e dependem da disponibilidade de entrega à experiência de cada extensionista.

\section{Visitas domiciliares - o encontro amoroso com o mundo popular}

A atividade de visitas domiciliares acontece aos sábados pelo período da manhã e são realizadas por duplas de estudantes de cursos diferentes, sendo que cada dupla acompanha as mesmas famílias toda semana, objetivando o desenvolvimento de vínculo e o exercício do trabalho interdisciplinar, tão caro à saúde.

No decorrer das atividades de acompanhamento às famílias, pude realizar visitas domiciliares semanais com uma estudante de psicologia, com quem formei uma dupla. Em diversas oportunidades, também realizei visitas com outros estudantes e professores de diferentes núcleos profissionais, o que possibilitou uma vivência interdisciplinar muito rica. 
A primeira família com a qual tive uma aproximação mais intensa era composta por três membros Rosa (mãe), Manoel (pai) e Zé (filho). Constantemente, esse microssistema recebia visitas longas de familiares do interior da Paraíba que, geralmente, vinham à cidade de João Pessoa por motivos de saúde. Assim, pude conhecer a dinâmica dessa família e a maneira como os seus membros se relacionavam.

A casa onde essa família morava tinha três cômodos pequenos - sala/cozinha, quarto e banheiro. Apesar da estrutura física precária, sentia-me bastante acolhida no espaço e, durante boa parte da manhã de visitas, sentia-me imersa em um mundo novo, cheio de encontro amoroso e de possibilidades de aprendizado.

Aos sábados pela manhã, após uma rápida reunião na Associação Comunitária Maria de Nazaré (Acoman), todos os extensionistas saíam em duplas para as visitas domiciliares. Ao chegar à casa de Rosa e cumprimentá-la com um abraço fraterno, sentávamos ao redor da mesa da cozinha, tirava o aparelho de verificar pressão arterial da minha bolsa e logo todos estavam reunidos para uma conversa informal.

Embora o procedimento técnico aproximasse as pessoas, ele não era o que as mantinha conosco até o fim da visita. Dialogávamos sobre os mais diversos assuntos - uso de medicações, namoro, trabalho, religião, Deus, escola, drogas, medo da chuva (a casa que eles moravam estava sob o risco de desabamento), dificuldade de atendimento médico, etc. Não havia muitas reclamações, mas pude perceber a dificuldade inerente aquele contexto de vida e a maneira criativa como eles a superavam, principalmente aquelas referentes à questão financeira - analisavam o que era mais essencial e planejavam os gastos com a saúde, com alimentação e manutenção da casa. Pegar ônibus só em ocasiões extremamente necessárias e como alternativas havia a bicicleta e a caminhada.

A maioria das famílias visitadas na comunidade apresenta relações conflituosas escancaradas, ou seja, nos primeiros encontros, o estudante já consegue identificar situações que precisam ser problematizadas e trabalhadas dialogicamente, buscando soluções coletivas. Ao contrário dessa maioria, a família que eu acompanhei era bastante organizada, os seus membros dialogavam e planejavam suas atividades diariamente. Os problemas existentes eram apenas estruturais, inerentes ao contexto socioeconômico no qual estavam inseridos e não pareciam afetar as relações afetivas entre eles.

Nesse sentido, a reflexão sobre as características dessa família, que difere da grande maioria das demais famílias acompanhadas pelo projeto, torna-se necessária. A primeira é a presença de um núcleo familiar bem estruturado e resolvido, ou seja, há um pai e uma mãe que têm suas relações baseadas na amorosidade e no respeito, refletindo na maneira como os filhos se relacionam no microssistema familiar e no mundo.

Outra característica importante dessa família é a dimensão da espiritualidade, traduzida pela busca religiosa, ou seja, a busca pelo divino e transcendental sem estar atrelado a uma religião específica. Fato evidenciado em algumas visitas nas quais presenciei a família reunida lendo a bíblia e falando sobre Deus. Tais características não representam a solução para os conflitos familiares das pessoas das classes populares em geral, porém são dimensões importantes para a formação da personalidade e trazem elementos presentes no que Paulo Freire chama ética universal do ser humano que tem no amor a base para a sua concepção?.

Ao experienciar esse tipo de organização familiar, o estudante extensionista tem acesso a dimensões afetivas intensas que, além de levantar questionamentos sobre a sua forma de relacionamento interpessoal e intrafamiliar, também reflete na maneira como o cuidado em saúde é concebido. Isso possibilita uma transformação, ou seja, passam-se de relações frias, estritamente técnicas para uma aproximação confiante, amorosa e empática.

Apesar desse microssistema familiar organizado e pouco conflituoso não necessitar de muitas intervenções, pude perceber que a aproximação com o contexto de vida dessas pessoas apresenta aspectos pedagógicos importantes, principalmente na perspectiva da formação de profissionais para atuar no SUS.

A presença do estudante no convívio com a família, conhecendo as suas dificuldades e as estratégias desenvolvidas para enfrentá-las, favorece a ampliação do olhar sobre a saúde, reconhecendo a necessidade de trabalhar além da doença e de partes do corpo físico. Nesse sentido, o estudante percebe a importância da integralidade do cuidado em saúde e aprende que as pessoas apresentam 
maneiras singulares de andar a vida, que estão associadas ao contexto social no qual estão inseridas. Percebe também que tais singularidades influenciam no processo de adoecimento e que a culpabilização do sujeito, prática comum no trabalho em saúde, precisa ser combatida, dado o seu caráter discriminante, preconceituoso e opressor em relação ao indivíduo que sofre.

Dessa maneira, pude aprender o que no ensino universitário não estava tão claro - a reconhecer as dificuldades inerentes a um contexto marginalizado e como atuar horizontalmente na construção de novas formas de cuidado em saúde. Aprendi a considerar o outro como incluso nessa construção e como protagonista do seu processo de adoecimento/cura; aprendi que o profissional de saúde, apesar de conhecer e ter domínio de alguns temas importantes para a prática educativa em saúde, não tem a capacidade de fazê-la deslocado do contexto de vida das pessoas e sem considerar previamente o saber e as práticas de saúde desenvolvidas no cotidiano do mundo popular. Aprendi que somos agentes de transformação e que essa transformação tão necessária começa nas nossas relações interpessoais diárias.

A visita domiciliar é uma atividade primordial no Pepasf, pois, por meio dela, o estudante adentra em espaços comunitários marginalizados e com estrutura física precária, conhece maneiras distintas de organização familiar e aprende, nos encontros informais, novas formas de pensar e fazer saúde . $^{8}$

Para Vasconcelos ${ }^{8}$, a abordagem do funcionamento familiar, que acontece por meio das visitas domiciliares na experiência desse projeto de extensão, tem sido bastante promissora, pois, no mundo popular, devido às impossibilidades financeiras e aos aspectos culturais, a vida torna-se penosa sem o apoio da família e outros elementos da rede de apoio social. Assim, a aproximação com esse microssistema se torna indispensável para o entendimento das dinâmicas próprias do mundo popular, capazes de interferir no processo saúde-doença.

Nesse sentido, os encontros semanais com a mesma família e a relação de confiança que se estabelece em cada conversa, favorece o desenvolvimento de vínculo. Na medida em que a relação de confiança se fortalece e as pessoas compartilham dimensões mais íntimas da sua vida, bem como as estratégias que adotam para lidar com os problemas de ordem familiar e social, os extensionistas se sentem mais estimulados a participar da busca de soluções para os problemas daquela família. $O$ vínculo que se constitui leva o estudante de saúde a contribuir com as pessoas na sua busca infinita de ser mais, a trabalhar com demandas inusitadas e diversas dos indivíduos e não apenas com procedimentos técnicos treinados na universidade ${ }^{8}$.

O vínculo afetivo e solidário desenvolvido inicialmente com as famílias visitadas, transforma-se em um vínculo cada vez mais amplo, ou seja, o vínculo familiar amplia-se para um com toda a comunidade e, posteriormente, com todos os oprimidos, subalternos e marginalizados do mundo. Observa-se, portanto, o desenvolvimento, no estudante, do compromisso social e com as causas populares.

Melo Neto ${ }^{9}$, teórico da Educação Popular, reconhece nas atividades do Pepasf uma intencionalidade política clara - a de querer formar profissionais com um novo olhar - e acrescenta que o estudante, ao procurar uma família para acompanhar, inverte o jeito de encarar a saúde, pois, nesse caso, não são os "pacientes" que procuram o estudante/profissional, mas o profissional que procura o "paciente". Fala também que, ao adentrar no espaço intrafamiliar, aproximando-se deste, o estudante irá aprender não somente a técnica estrita de sua competência, mas estará se envolvendo em questões espirituais presentes na cultura das comunidades e poderá perceber que a saúde tem uma dimensão social, que ela está em uma pessoa, mas também é um produto social.

Nesse sentido, o acompanhamento familiar, por meio das visitas domiciliares, constitui uma ferramenta presente na Extensão Popular que, além de contribuir para a formação de profissionais de saúde mais humanos, éticos, comprometidos, dialógicos e lutadores da saúde, também contribui para o crescimento e amadurecimento pessoal. Essa experiência faz com que o estudante tenha acesso a novas formas de relacionamento em sociedade, ampliando da interação apenas entre os seus semelhantes para uma relação entre os diferentes - os mais avantajados se misturam com o mundo popular. Essa aproximação gera estranhamentos mútuos, inquieta e leva os envolvidos a uma reflexão crítica sobre o seu posicionamento no mundo.

Vale ressaltar que os aprendizados advindos dessa experiência são singulares de cada extensionista, pois cada família acompanhada é diferente, ou seja, possui maneiras ímpares de organização e de 
interação social. Nesse sentido, os estudantes extensionistas têm acesso a aprendizados únicos, muito embora existam elementos presentes nessa atividade que se assemelham, tais como: vínculo com a família, amorosidade, afetividade e a experimentação de novas formas de cuidado com o outro.

\section{Reuniões semanais - aprendendo a trabalhar em grupo}

As reuniões semanais do grupo de extensionistas, envolvendo os professores e estudantes, acontecem toda segunda-feira na UFPB. Essas reuniões são organizadas de forma a alternar momentos de discussão teórica, momentos de discussão de casos acompanhados na comunidade e momentos destinados à organização das atividades. Nas discussões teóricas, são trabalhados temas relativos à Educação Popular em Saúde e outros assuntos, conforme a necessidade do grupo; nas reuniões para discussão de casos, os estudantes trazem para a roda de conversa de problemas enfrentados junto à família acompanhada ou aprendizados relativos à sua atuação na comunidade; e, nas reuniões organizativas, acontecem avaliação e planejamento de atividades.

A participação dos extensionistas de maneira mais ativa nas reuniões do Pepasf acontece gradativamente, pois, para um estudante acostumado com a opressão da educação bancária, ainda predominante no mundo acadêmico, torna-se difícil adentrar em espaços mais dialógicos sem passar por, no mínimo, algum estranhamento. Nesse contexto, permaneci por muitos encontros em silêncio, tímida e não me posicionava como alguém disposta a contribuir com a organização do Pepasf. A inserção nas atividades organizativas foi acontecendo aos poucos, ao perceber-me parte do processo, ao ser acolhida sem julgamentos, ao entender que não havia barreiras entre os professores e os estudantes, todos estavam imersos numa construção coletiva.

Com a inserção mais ativa nas reuniões do projeto, pude aprender a trabalhar em grupo, respeitando as diferentes maneiras de pensar e os posicionamentos dos envolvidos; valorizar e respeitar o tempo que cada sujeito tem para seu amadurecimento individual ou em sociedade; aprendi que o estudante pode se posicionar contrário ao professor e que é nas contradições, na problematização, que o aprendizado se torna mais rico; aprendi a errar e a aprender com o meu erro; a acolher o outro; a construir, construir junto, pensar junto, fazer junto.

Esses aprendizados contribuem imensamente para a atuação profissional junto ao SUS, pois o trabalho coletivo e interdisciplinar constitui a base para um cuidado em saúde rico e integral. Exige, portanto, que saibamos dialogar e nos relacionar horizontalmente, que a situação de saúde a ser discutida seja problematizada, que os diversos atores se posicionem numa construção coletiva e, dessa maneira, planos de cuidado compatíveis com a individualidade de cada sujeito sejam pensados e elaborados.

O trabalho interdisciplinar contempla, entre outros aspectos, a possibilidade de trabalho conjunto, que respeita as bases disciplinares específicas, mas busca soluções compartilhadas para os problemas das pessoas ${ }^{10}$ e esbarra na formação dos profissionais de saúde que tendem a privilegiar o trabalho individual em relação ao coletivo ${ }^{11}$, o que prejudica a integração da equipe e a aplicação da prática necessária ao cuidado integral.

As reuniões semanais, na universidade, também contribuem para o desenvolvimento da autonomia dos extensionistas. Entende-se por autonomia o direito da pessoa de decidir sobre si mesma e de agir segundo a sua vontade, sem constrangimento de qualquer força externa. Abrange também o fortalecimento das pessoas para decisões que precisam ser tomadas, em relação à conquista de suas próprias necessidades ${ }^{12}$.

Nesse contexto, a Extensão Popular tem um caráter facilitador da autonomia devido à sua descentralização, ou seja, as atividades do Pepasf não estão centradas na figura de professores ou de um grupo deles, mas, com seu apoio, os estudantes tomam a frente do processo de trabalho do projeto, desenvolvendo atividades de planejamento, de avaliação, de discussão teórica e de organização mais geral das ações no Pepasf. 
Assim, os estudantes extensionistas, ao se inserirem nas atividades mais organizativas do projeto, passam a se responsabilizar pela construção das dinâmicas dos encontros, elaborando maneiras criativas de favorecer o diálogo no grupo, o que exige certa apropriação teórica da EP e seus métodos de trabalho.

Essa aproximação prática e teórica da EP, bem como do trabalho em grupo, favorece o desenvolvimento da autoconfiança do estudante extensionista, da sua capacidade de posicionamento humilde e firme, da estruturação do conteúdo e da segurança da própria fala. Há, portanto, um amadurecimento estudantil, o que propicia ao extensionista habilidade em participar de encontros mais amplos da EP, destreza em debates conflituosos e engajamento em lutas e embates políticos mais intensos.

O desenvolvimento da autonomia é um aspecto importante para a atuação profissional junto ao SUS, pois o trabalho em saúde é também um trabalho político, sendo necessário que o profissional esteja apto a defender posicionamentos e tenha firmeza no enfrentamento de situações opressoras e autoritárias. Os estudantes que desenvolveram autonomia vão se percebendo cidadãos no enfrentamento de autoridades, tendo voz e força na vida pública, fato que repercute positivamente na vida do extensionista, pois melhora sua autoestima e os torna destemidos no enfrentamento, até mesmo, de situações familiares de opressão ${ }^{13}$.

As Diretrizes Curriculares Nacionais para os cursos de saúde apontam novos caminhos para a formação profissional em saúde, considerando a atuação junto ao SUS. Definem o perfil de um profissional de saúde generalista, humanista, crítico e reflexivo, ético e que saiba atuar interdisciplinarmente, rumo à atenção integral. Enquanto a implementação dessas novas diretrizes ainda está em andamento nas Instituições de Ensino Superior (IES) de todo o Brasil, a Extensão Popular tem sido um diferencial na formação profissional em saúde, trabalhando, por meio da EP, elementos como o diálogo, o trabalho em equipe e interdisciplinar, a autonomia e o protagonismo estudantil e comunitário, a participação popular, a humanização, além do incentivo às práticas alternativas de cuidado - em uma aproximação confiante, amorosa e afetiva.

\section{Articulação política comunitária - uma história de lutas e conquistas}

A Comunidade Maria de Nazaré é conhecida na cidade por suas lutas e articulações políticas. Depois de algum tempo no projeto e com a mudança da família que eu acompanhava para outra comunidade, inseri-me mais ativamente nas atividades da Associação Comunitária Maria de Nazaré (Acoman) e, dessa maneira, pude engajar-me na luta dos moradores por melhorias nas suas condições de vida. No entanto, essa área de atuação é pouco procurada pelos extensionistas do Pepasf devido à dificuldade de conciliação entre as reuniões de articulação política - que não apresentam horário regular e acontecem de acordo com as demandas da comunidade - e as atividades curriculares obrigatórias da graduação.

Além disso, a atividade de articulação política comunitária não é uma exigência para o cumprimento da carga horária da extensão (12 horas) como as demais atividades e, embora seja estimulada a participação nesses espaços, ela é pouco valorizada pelos estudantes.

A baixa procura ainda não tem motivos conhecidos, mas, no geral, o que se observa é que o engajamento dos extensionistas nessas atividades é proporcional ao tempo de vivência na Extensão Popular. Tal fato pode estar associado à imaturidade dos estudantes que procuram a extensão estudantes do início do curso, com pouca apropriação da EP e com pouco amadurecimento crítico e político - e à dedicação inicial às famílias visitadas, dado o vínculo que se estabelece nesse processo.

Apesar dessa pouca participação, a inserção dos estudantes nos movimentos sociais que não são dominados por políticos clientelistas se revela muita rica, pois aponta para novos e criativos caminhos de atenção à saúde. Além disso, os estudantes desenvolvem formas inovadoras de luta social pela saúde e de apoio solidário aos moradores em situações especiais de crise $e^{8}$.

A Comunidade Maria de Nazaré surgiu da ocupação de uma área pública e, desde o seu início, esteve vinculada ao movimento de luta pela moradia. Minha inserção política inicial foi nesse movimento, o qual estava presente em todos os espaços de reivindicação. A comunidade clamava por melhorias na sua infraestrutura e habitação social. 
O movimento de luta pela moradia da Comunidade Maria de Nazaré ganhou mais visibilidade social com as plenárias do orçamento democrático. Estas aconteciam anualmente e tinham como objetivo principal a participação da população na definição de prioridades para as ações estratégicas da gestão municipal. Durante as plenárias, a população de cada região votava na principal demanda da sua comunidade/bairro e, posteriormente, poderia se inscrever para a fala de reivindicação ou defesa de propostas junto ao prefeito e secretários municipais.

Nesses encontros, a maioria dos moradores fazia falas isoladas, reivindicando calçamentos para sua rua, praças para o bairro, etc., porém, as lideranças da Acoman, em parceria com a Extensão Popular, organizavam sua proposta em um documento que era lido e entregue em seguida aos secretários responsáveis pela infraestrutura e pela habitação social. Foi dessa maneira que a luta pela moradia foi ouvida, em um movimento organizado, propositivo, dialógico e participativo.

Após as reivindicações da Comunidade Maria de Nazaré, um projeto de reurbanização da Comunidade foi encaminhado pelo município ao governo federal e aprovado, no ano de 2010. Esse projeto garante aberturas de ruas e pavimentação, sistema de drenagem, praça, centro comunitário, três tipos de habitações, entre outras melhorias para a população.

O projeto de urbanização não abrangia a construção de uma Unidade Básica de Saúde (UBS) que continuaria a ocupar um espaço improvisado ou então seria transferido para uma unidade integrada distante da comunidade. Essas situações foram pensadas e problematizadas em reuniões com a Equipe de Saúde da Família, Acoman e o grupo do projeto de Extensão Universitária e, desse processo, iniciou-se a mobilização por uma UBS próxima a Comunidade. Reivindicamos junto ao orçamento democrático, junto à Secretaria Municipal de Saúde, articulamos com a Secretaria Municipal de Habitação Social (Semhab) e, desse processo de construção coletiva, conseguimos a aprovação de um projeto para a construção de uma UBS numa localidade próxima da Comunidade.

Com o engajamento nos processos democráticos de luta, aprendi a força que o povo organizado possui na conquista por seus direitos sem que haja, necessariamente, o embate físico, mas um processo dialógico, com proposições coerentes e visando ao bem coletivo. Aprendi que proporcionar espaços de participação popular torna o trabalho em saúde mais rico, pois, dessa maneira, a população sentese responsável, atuante e protagonista na construção de estratégias que possibilitem uma vida mais saudável, sem que haja imposições, mas empoderamento e autonomia no cuidado com a sua saúde.

Aprendi, também, que o profissional de saúde não deve estar distante das demandas da comunidade, atuando apenas no problema ou na doença, precisa conhecer os processos de articulação política e se engajar, participando junto com o povo em busca da justiça social.

\section{Conclusão}

A experiência na Extensão Popular tem sido relatada como diferencial positivo para a formação profissional em saúde ${ }^{14}$. Elementos presentes na Educação Popular se incorporam às ações de saúde dando um novo significado para o trabalho profissional junto ao sujeito em sofrimento, seja físico, psíquico, espiritual ou estrutural.

No entanto, a extensão de caráter popular ainda corresponde a uma atividade alternativa diante do ensino universitário e, por essa razão, muitos estudantes de saúde terminam sua graduação sem ter contato com os métodos e concepções políticas da EP, reproduzindo as práticas tradicionais e verticais no trabalho em saúde. Nesse contexto, uma formação universitária em saúde que esteja atrelada aos princípios da EP pode favorecer mudanças na maneira como o cuidado em saúde é concebido e praticado nos diversos níveis de atenção ao usuário do SUS.

Outro aspecto que merece atenção de futuras pesquisas é a atuação profissional junto ao SUS de egressos da Extensão Popular, pois ao deparar, no ambiente de trabalho, com profissionais de saúde que realizam uma prática clínica individualizada ou com uma gestão de serviços públicos autoritária que priva a liberdade dos sujeitos, o profissional que teve uma formação diferenciada esbarra em grandes dificuldades para implementar os princípios do SUS. 
Nesse sentido, está sendo desenvolvida uma pesquisa, em nível de mestrado, buscando apreender as dificuldades e potencialidades do profissional egresso da Extensão Popular na atuação junto ao SUS, tendo como base a experiência aqui relatada. Espera-se que, ao avaliar a prática da Extensão Popular, bem como a implementação dos aprendizados advindos dessa experiência no SUS, o processo de trabalho nos serviços públicos de saúde possa ser refletido rumo a melhorias para o trabalhador de saúde e para o usuário.

\section{Colaboradores}

Maria Francilene Leite foi responsável pelo fornecimento das informações referentes à sua experiência e os demais autores colaboraram na análise final do manuscrito.

\section{Referências}

1. Freire P. Pedagogia do oprimido. Rio de Janeiro: Paz e Terra; 2011.

2. Vasconcelos EM. Educação Popular, um jeito de conduzir o processo educativo. In: Vasconcelos EM, Cruz PJSC, organizadores. Educação popular na formação universitária: reflexões com base em uma experiência. São Paulo: Hucitec; 2011. p. 28-34.

3. Ribeiro KSQS. A experiência na extensão popular e a formação acadêmica em fisioterapia. Cad Cedes. 2009;29(79):335-46.

4. Melo Neto JF. Extensão popular. João Pessoa: Editora UFPB; 2006.

5. Cruz PJSC. Extensão popular: a reinvenção da universidade. In: Vasconcelos EM, Cruz PJSC, organizadores. Educação popular na formação universitária: reflexões com base em uma experiência. São Paulo: Hucitec; 2011. p. 40-61.

6. Queiroz DT, Vall J, Souza AMA, Vieira NFC. Observação participante na pesquisa qualitativa: conceitos e aplicações na área da saúde. Rev Enferm UERJ. 2007;15(2):276-83.

7. Freire P. Pedagogia da autonomia. São Paulo: Paz e Terra; 2011.

8. Vasconcelos EM. Educação Popular e o movimento de transformação da formação universitária no campo da saúde. In: Vasconcelos EM, Cruz PJSC, organizadores. Educação popular na formação universitária: reflexões com base em uma experiência. São Paulo: Hucitec; 2011. p. 362-98.

9. Melo Neto JF. Extensão Popular: a universidade em movimento. In: Vasconcelos EM, Cruz PJSC, organizadores. Educação popular na formação universitária: reflexões com base em uma experiência. São Paulo: Hucitec; 2011. p. 406-14.

10. Saupe R, Cutolo LRA, Wendhausen ALP, Benito GAV. Competência dos profissionais da saúde para o trabalho interdisciplinar. Interface (Botucatu). 2005;9(18):521-36.

11. Loch-Neckel G. Desafios para a ação interdisciplinar na atenção básica: implicações relativas à composição das equipes de saúde da família. Cienc Saude Colet. 2009;14(1):1463-72.

12. Batista PSS. Ética no cuidado em saúde e na formação universitária na perspectiva da educação popular [tese]. João Pessoa (PB): Universidade Federal da Paraíba; 2012.

13. Vasconcelos EM. Formar profissionais de saúde capazes de cuidar do florescer da vida. In: Vasconcelos EM, Frota LC, SIMON E, organizadores. Perplexidade na universidade: vivências nos cursos de saúde. São Paulo: Hucitec; 2006. p. 265-308.

14. Vasconcelos EM, Cruz PJSC, organizadores. Educação popular na formação universitária: reflexões com base em uma experiência. São Paulo: Hucitec; 2011. 
Este relato objetiva abordar la influencia de la "Extensão Popular" en la formación académica en salud para el SUS, considerando la vivencia de una estudiante de enfermería. Se considerarán los aprendizajes adquiridos en las actividades desarrolladas en el Projeto Educação Popular e Atenção à Saúde da Família (PEPASF): visitas domiciliares, reuniones semanales y espacios de articulación política comunitaria. Las visitas domiciliares semanales acercan al estudiante del mundo popular que, por vínculo, desarrolla nuevas maneras de pensar y hacer salud; las reuniones semanales trabajan principios de interdisciplinaridad rumbo al trabajo integral en salud y; en los espacios de articulación comunitaria, el estudiante se enrola en las luchas y aprende a estimular la participación popular. La "Extensão Popular" constituye una alternativa frente a la enseñanza en la universidad que ha contribuido para una formación en salud coherente con los principios del SUS.

Palabras clave: Educación popular. Extensão popular. Formación Académica en Salud. Sistema Único de Salud.

\section{Popular Extension in professional training in health for SUS: reflecting an experience}

This study aims to address the influence of Popular Extension in university education in health for SUS, considering the experiences of a nursing student. It will be considered the learnings acquired in the activities developed by the Projeto Educação Popular e Atenção à Saúde da Família (PEPASF): home visits, weekly meetings and community political activities. The weekly home visits approaches the students to the popular world, by creating ties, and making them develop new ways of thinking and doing health; the weekly meetings work the principles of interdisciplinary towards integral health; and in the spaces of community articulation the students engage in conflicts and learn to stimulate popular participation. The Popular Front Extension is an alternative to teaching at the university that has contributed to a health training consistent with the principles of the SUS.

Keywords: Popular education. Popular extension. University education in health. Unified Health System.

\section{Extensão Popular na formação profissional em saúde para o SUS: refletindo uma experiência}

O presente relato objetiva abordar a influência da Extensão Popular na formação universitária em saúde para o SUS, considerando a vivência de uma estudante de enfermagem. Serão considerados os aprendizados adquiridos nas atividades desenvolvidas no Projeto Educação Popular e Atenção à Saúde da Família (Pepasf): visitas domiciliares, reuniões semanais e nos espaços de articulação política comunitária. As visitas domiciliares semanais aproximam o estudante do mundo popular que, por meio do vínculo, desenvolve novas maneiras de pensar e fazer saúde; as reuniões semanais trabalham princípios da interdisciplinaridade rumo ao trabalho integral em saúde e; nos espaços de articulação comunitária, o estudante se engaja nas lutas e aprende a estimular a participação popular. A Extensão Popular constitui uma alternativa ante o ensino na universidade que tem contribuído para uma formação em saúde coerente com os princípios do SUS.

Palavras-chave: Educação popular. Extensão popular. Formação universitária em saúde. Sistema Único de Saúde. 
